\title{
Neuropeptides: Central Nervous System Effects on Nutrient Metabolism
}

\author{
M. Brown \\ Peptide Biology Laboratory, The Salk Institute, San Diego, California, USA
}

Summary. Several neural peptides have been demonstrated to influence central nervous system control of nutrient metabolism. The principal mechanism by which these peptides influence peripheral nutrient metabolism is by altering the secretion of adrenal epinephrine. Bombesin or its mammalian counterpart, gastrin releasing peptide, and TRF act within the brain to stimulate the secretion of epinephrine from the adrenal gland. Associated with these changes in epinephrine secretion is a reduction of plasma insulin and elevation of plasma glucagon and glucose. Somatostatin and various somatostatin analogs act in the brain to inhibit adrenal epinephrine secretion stimulation by a variety of stimuli.

Key words: CNS control of metabolism, adrenal epinephrine secretion, CNS action of neuropeptide

The central nervous system can potentially modify nutrient metabolism or other visceral functions by one of three efferent mechanisms. The first of these is a humorally mediated control principally exerted by hypothalamic-pituitary hormone secretion, including growth hormone, thyrotropin, corticotropin. The second mechanism by which the central nervous system influences peripheral nutrient metabolism is by alterations of autonomic nervous system activity. A third mechanism could be via brain secretion of humoral substances which could modify peripheral metabolism directly. Although substances have been described to be present in hypothalamus which are capable of modifying pancreatic insulin and glucagon secretion $[15,17]$, there is no evidence that these substances are released into the blood. A variety of studies have previously demonstrated, using lesion or stimulation methods, that the central nervous system is capable of exerting influence over peripheral metabolism of nutrients $[14,23]$. The emergence of neuropeptides as a new class of intercellular brain messenger substances has led to studies assessing the role of these peptides in the CNS control of visceral functions. This paper will discuss the CNS actions of bombesin, thyrotropin releasing factor (TRF), somatostatin and somatostatin analogues to influence peripheral glucose metabolism.

\section{Bombesin}

Bombesin is a 14 amino acid peptide originally isolated from frog skin by Erspamer and colleagues [12]. Recently a mammalian bombesin, termed gastrin releasing peptide (GRP), has been isolated and characterized [16]. Bombesin and GRP share a common decapeptide and moreover show identity in their actions in several biological assay systems [5] (Table 1). Bombesin immunoactivity, which probably represents a GRP-like peptide, is found in mammalian brain $[9,18]$. Highest concentrations of

Table 1. Structures of the frog skin peptide, bombesin, and gastrin releasing peptide, a mammalian bombesin

\footnotetext{
Bombesin

pGlu-Gln-Arg-Leu-Gly-Asn-GIn-Trp-Ala-Val-Gly-His-LeuMet- $\mathrm{NH}_{2}$

Gastrin releasing peptide (GRP)

Ala-Pro-Val-Ser-Val-Gly-Gly-Gly-Thr-Val-Leu-Ala-Lys-

Met-Thr-Pro-Arg-Cly-Asn-His-Trp-Ala-Val-Gly-His-Leu-

Met- $-\mathrm{NH}_{2}$
}

Note should be made of the C-terminal homology of these peptides. Both peptides produce identical biological actions in several bioassay systems 


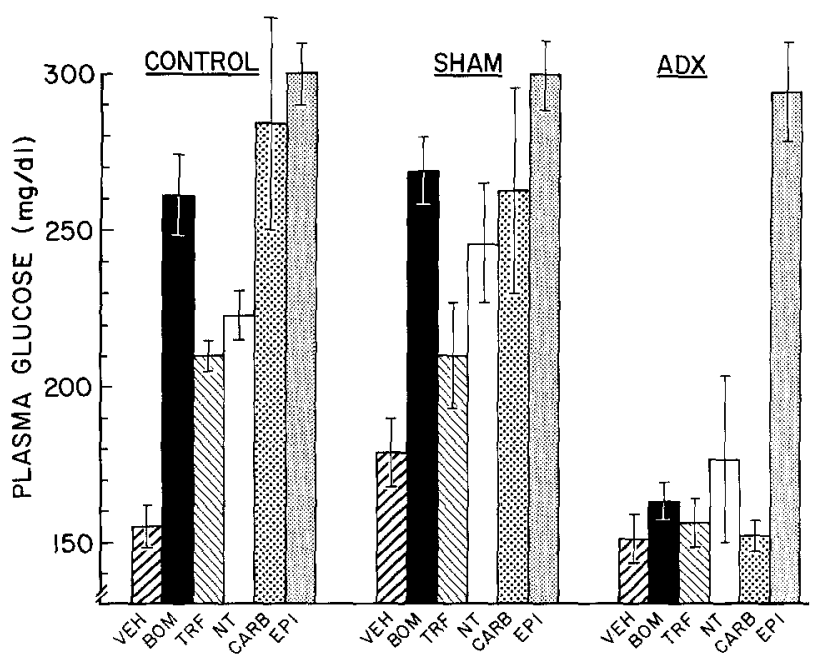

Fig. 1. Adrenalectomy (ADX) prevents bombesin (bom; $100 \mathrm{ng}$ ), thyrotropin releasing factor (TRF; $1 \mu \mathrm{g}$ ), neurotensin (NT; $100 \mu \mathrm{g}$ ) and carbachol (carb; $1 \mu \mathrm{g}$ ) induced hyperglycaemia. These substances were given intracisternally to freshly adrenalectomized rats and blood glucose examined 20 min later. Epinephrine $(5 \mu \mathrm{g})$ given SC produces hyperglycaemia in adrenalectomized rats, thus showing animal's ability to respond to peripheral glucogenic stimuli

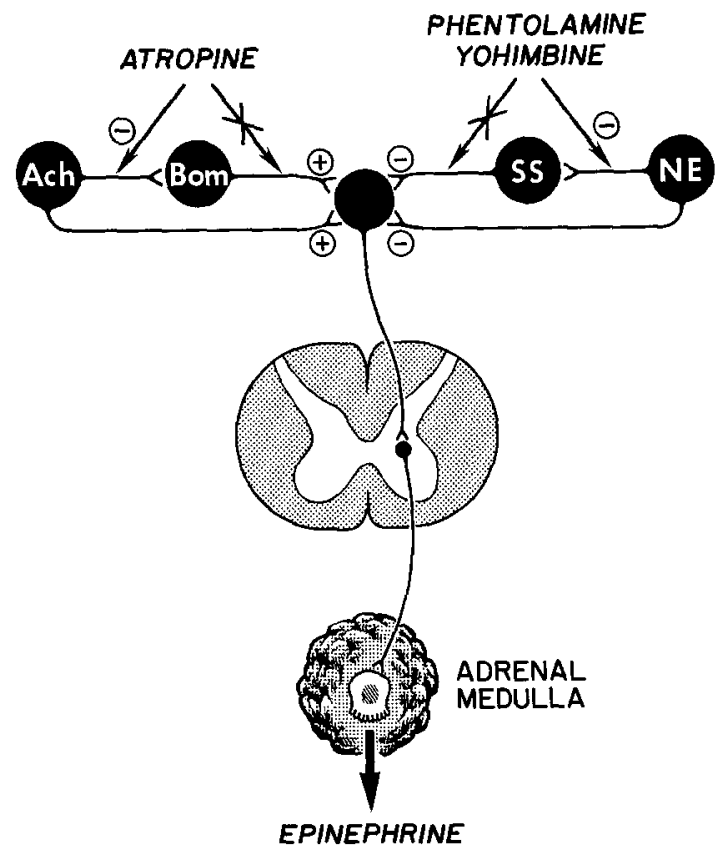

Fig. 2. CNS cholinergic pathways do not mediate bombesin CNSstimulated adrenal epinephrine secretion since atropine prevents carbachol $(1 \mu \mathrm{g})$ CNS induced epinephrine secretion but does not inhibit bombesin CNS-induced epinephrine secretion. CNS $\alpha$ adrenergic pathways do not mediate somatostatin (or somatostatin analogue) CNS inhibition of adrenal epinephrine secretion since neither phentolamine ( $\alpha_{1}$ antagonist) nor yohimbine ( $\alpha_{2}$ antagonist) prevent somatostatin (or somatostatin analogue) CNS inhibition of epinephrine secretion bombesin-like peptide $[9,18]$ and receptors [19] are in the hypothalamus and several brainstem nuclei. Bombesin-like peptide is also found in the gastrointestinal tract with highest concentrations in the stomach mucosa $[9,18,21,27]$. Bombesin has pharmacologic actions to influence gastrointestinal and CNS activities [4].

Intracisternal (IC) or intracerebroventricular (ICV) administration of bombesin results in a prompt and sustained elevation of plasma glucose $[6,8]$. This elevation of plasma glucose is not secondary to changes in peripheral glucose turnover, is not prevented by hypophysectomy, is prevented by adrenalectomy (Fig. 1) and is associated with dramatic elevations of plasma epinephrine, glucagon and reduction of plasma insulin [8]. Since peripheral administration of bombesin does not produce these hormonal changes, it has been concluded that bombesin acts within some as yet undetermined CNS site to produce an adrenal medullary dependent hyperglycaemia in rats. Other studies have concluded that the mechanism by which hyperglycaemia develops in these animals is dependent on epinephrine induced changes in pancreatic insulin and glucagon secretion and not secondary to direct hepatic action of epinephrine to increase glucose production [8]. Attempts to identify the site of action of bombesin in changing adrenal epinephrine secretion have been unsuccessful. However, the anterior hypothalamic preoptic region does not appear to be involved in mediating this response. Studies have indicated that the effects of bombesin on temperature regulation result from bombesin actions in anterior hypothalamic preoptic region [20]. The recent demonstration of bombesin-like peptide in brain-stem nuclei [18] associated with sympathetic outflow suggests the possibility that bombesin might influence adrenal medullary sympathetic outflow at these sites. The structural specificity of bombesin in producing hyperglycaemia is supported by the observations that various analogues of bombesin with $\mathrm{C}$ terminal modifications are totally inactive in this respect [22]. A variety of other unrelated peptides also failed to produce hyperglycaemia. Three other peptides tested have been found to produce varying degrees of CNS dependent hyperglycaemia in rats. High doses of neurotensin $(100 \mu \mathrm{g})$ given intracisternally produce an adrenal medullary dependent hyperglycaemia [2] (Fig. 1). $\beta$-Endorphin, administered IC or ICV at doses which produce marked changes in motor behaviour or quadraplegia, also produces a hyperglycaemia that does not appear to be dependent on the adrenal gland [2]. Finally, TRF given IC or ICV produces a transient adrenal medullary dependent hyperglycaemia as will be discussed 
below. Dependence of bombesin's action in producing hyperglycaemia on other known endogenous neurotransmitter agents cannot be demonstrated. The cholinergic agonist, carbachol, placed IC or ICV produces an adrenal medullary dependent hyperglycaemia similar to bombesin [8] (Fig. 1). This carbachol induced hyperglycaemia is totally prevented by IC or ICV administration of atropine. However, bombesin induced hyperglycaemia is not prevented by atropine [8] (Fig. 2). These results would appear to exclude the possibility that bombesin induced hyperglycaemia is dependent on brain cholinergic pathways. Whether or not carbachol induced hyperglycaemia ist dependent on a brain endogenous bombesin-ergic system remains to be determined.

The effects of bombesin on the adrenal medullary sympathetic outflow are reversible and dose-dependent [8]. Furthermore, the actions of bombesin on adrenal medullary epinephrine secretion are totally abolished by administration of various somatostatin analogues as will be discussed below. Attempts to prevent bombesin activation of adrenal medullary epinephrine secretion by administration of centrally acting $\alpha$-adrenergic agonists such as clonidine have been unsuccessful, thus suggesting that central $\alpha$ adrenergic tone does not influence bombesin-ergic pathways (Brown, unpublished data). Identification of the site of action of bombesin and development of methods to inhibit its endogenous effects will enable further investigation into the physiological role of endogenous bombesin-like peptide as a regulator of adrenal medullary sympathetic nervous system outflow, and peripheral nutrient metabolism.

\section{TRF}

We have recently demonstrated that IC or ICV administration of TRF produces a transient elevation of plasma epinephrine, glucagon and glucose which like the hyperglycaemia produced by bombesin is prevented by adrenalectomy (Brown, unpublished data) (Fig. 1). In contrast to bombesin which does not produce any apparent effects on cardiovascular sympathetic activity or parasympathetic activity [3], TRF has been demonstrated to produce elevations in heart rate and blood pressure $[1,11]$, suggesting more generalized activation of sympathetic activity. TRF also increases gastric secretion of acid and fluid [25], and colonic activity, suggesting that this peptide increases parasympathetic outflow [24]. It is evident that while both bombesin and TRF produce elevations of adrenal medullary epinephrine secretion, they have different general patterns of influence on the autonomic nervous system. Like bombesin, TRF

$$
\begin{gathered}
\text { SOMATOSTATIN } \\
\text { Ala - Gly - Cys - Lys - Asn - Phe - Phe - Trp } \\
\text { Cys - Ser - Thr - Phe - Thr - Lys } \\
\text { des } \left.A^{1,2,4,5,12,13[D-T r p}{ }^{8}\right] \text {-SOMATOSTATIN } \\
\text { Cys - Phe - Phe - [D-Trp }] \\
\text { Cys - Phe - Thr - Lys }
\end{gathered}
$$

Fig. 3. Structure of somatostatin and a synthetic analogue of somatostatin, desAA $\mathrm{A}^{1,2,4,5,12,13}\left[\mathrm{D}-\mathrm{Trp}^{8}\right]$-somatostatin (ODT8-SS). ODT8-SS is similar to somatostatin in that it inhibits the secretion of growth hormone and insulin and at high doses the secretion of glucagon [26]

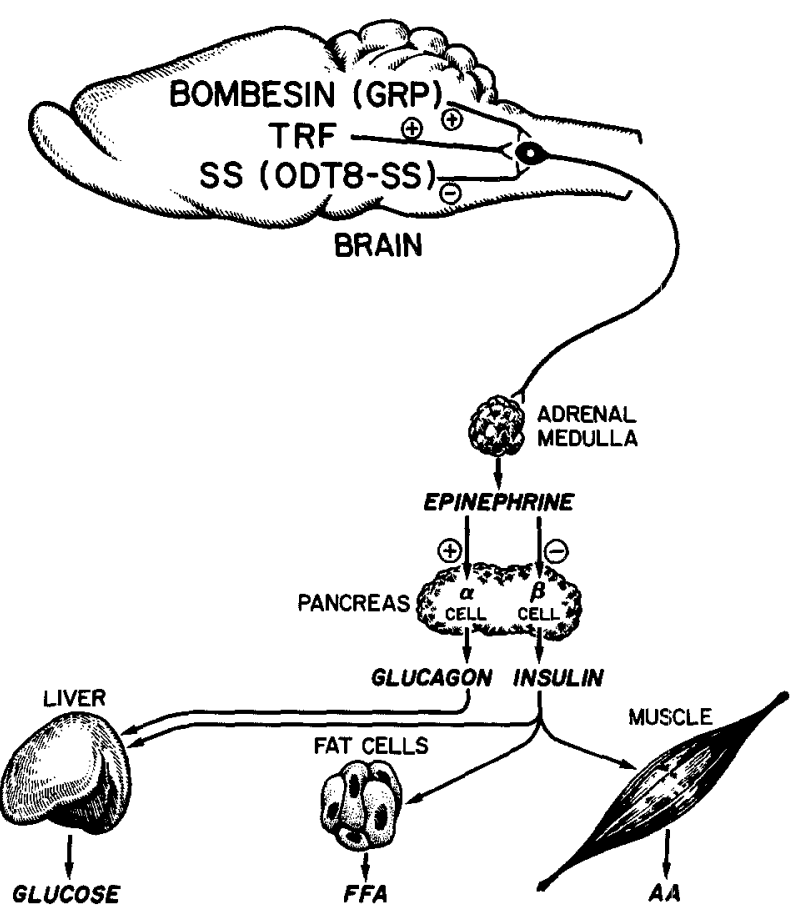

Fig. 4. Summary of the action of TRF, bombesin and somatostatin (somatostatin analogues) to act within the CNS to influence peripheral nutrient metabolism

is anatomically distributed in various CNS regions which may potentially be involved in determining autonomic nervous system outflow [10].

\section{Somatostatin and Somatostatin Analogues}

Somatostatin and various analogues of somatostatin have been reported to act within the CNS to prevent the hyperglycaemia induced by IC administration of 
bombesin, carbachol, neurotensin and 2-deoxyglucose as well as stress induced hyperglycaemia [7]. The conclusion that these actions result from $\mathrm{CNS}$ effects of somatostatin or some of its analogues is based on the observation that doses of peptide which were ineffective when given peripherally to prevent hyperglycaemia, were effective when given in the brain. In addition, certain analogues of somatostatin given peripherally produce hyperglycaemia but when given IC or ICV prevent hyperglycaemia induced by bombesin, carbachol, 2-deoxyglucose (2DG) and stress [7]. Studies to characterize the mechanism of action of somatostatin analogue inhibition of CNS dependent hyperglycaemia have resulted in the observation that these analogues prevent adrenal medullary epinephrine secretion. The somatostatin analogue, desAA ${ }^{1,2,4,5,12,13}\left[\mathrm{D}-\operatorname{Trp}^{8}\right]$-somatostatin (ODT8-SS) (Fig. 3), given ICV prevents the elevation of plasma epinephrine induced by bombesin, carbachol, 2DG, stress, and insulin induced hypoglycaemia $[2,13]$. The site of action of somatostatin or its analogues to produce these effects is as yet undetermined.

ODT8-SS given IC or ICV appears to have other actions on sympathetic outflow as demonstrated by somatostatin or somatostatin analogue lowering of blood pressure in normal or spontaneously hypertensive animals $[2,11,28]$. Brain somatostatin pathways do not appear to be dependent on central $\alpha$-adrenergic tone, to inhibition of sympathetic outflow, since administration of phentolamine and yohimbine do not prevent effects of this analogue (Brown, unpublished data) (Fig. 2).

Studies carried out with bombesin, TRF, somatostatin and its analogues demonstrate that brain peptidergic system are capable of modifying adrenal medullary sympathetic outflow and peripheral nutrient metabolism (Fig. 4). The observation that ODT8-SS prevents changes in adrenal medullary sympathetic outflow and glucose metabolism associated with IC administration of bombesin, carbachol, insulin, 2DG, and stress, demonstrates the importance of adrenal medullary activities in mediating the CNS glucoregulatory actions of these various treatments. These studies in no way exclude the possible importance of direct pancreatic or hepatic innervation by the autonomic nervous system in regulating carbohydrate metabolism. The use of these peptides as pharmacologic probes to further investigate neural mechanisms in the regulation of carbohydrate metabolism may enlighten our understanding of the physiological participation of the brain in the control of peripheral nutrient metabolism. The importance of these observations in various diseases states such as diabetes mellitus is of interest and may shed some light on the mechanisms of stress induced hyperglycaemia, and the role of the central nervous system in diabetes.

Acknowledgements. This research was conducted in part by The Clayton Foundation for Research, California Division. M. Brown is a Clayton Foundation Investigator. Research supported by NINCDS grant NS14263, NIAMDD grant AM29017 and The American Diabetes Association. Thanks to Dr. Jean Rivier for the synthesis of peptides, to Roberta Allen, Vicki Webb, Winny Bartholomeus, and Greta Berg for expert technical assistance and to Susan McCall Garonski for manuscript preparation.

\section{References}

1. Beale JS, White RP, Huang SP (1977) EEG and blood pressure effects of TRH in rabbits. Neuropharmacology 16 : 499-506

2. Brown MR, Fisher DA (in press) Glucoregulation and the sympathetic nervous system: CNS control by brain peptides. In: Bloom F (ed) Peptides: Integrators of cell and tissue functions. Society of Genetic Physiologists

3. Brown M, Taché Y (in press) Hypothalamic peptides: Central nervous system control of visceral functions. Fed Proc

4. Brown M, Vale W (1979) Bombesin: Putative mammalian neurogastrointestinal peptides. Trends Neurosci 2: 95-97

5. Brown M, Märki W, Rivier J (1980) Is gastrin releasing peptide mammalian bombesin? Life Sci 27: 125-128

6. Brown MJ, Rivier J, Vale W (1977) Bombesin affects the central nervous system to produce hyperglycemia in rats. Life Sci 21: 1729-1734

7. Brown M, Rivier J, Vale W (1979) Somatostatin; Central nervous system actions of glucoregulation. Endocrinology 104: 1709-1715

8. Brown M, Taché Y, Fisher D (1979) Central nervous system action of bombesin: Mechanism to induce hyperglycemia. Endocrinology 105: 660-665

9. Brown MR, Allen R, Villarreal J, Rivier J, Vale W (1978) Bombesin-like activity: Radioimmunologic assessment in biological tissues. Life Sci 23: 2721-2728

10. Brownstein MJ, Palkovits M, Saavedra MJ, Bassir RM, Utiger RD (1974) Thyrotropin-releasing hormone in specific nuclei of rat brain. Science 185: 267-269

11. Delbarre B, Senon D, Schmitt H (1977) Cyclic 3'5'-adenosine monophosphate and central circulatory control in cats and dogs. Clin Exp Pharmacol Physiol 4: 341-348

12. Erspamer V, Melchiorri P (1975) Actions of bombesin on secretions and motility of the gastrointestinal tract. In: Thompson JC (ed) Gastrointestinal hormones. University of Texas Press, Austin, p 575

13. Fisher DA, Brown M (1980) Somatostatin: Plasma catecholamine suppression mediated by the central nervous system. Endocrinology 107: 714-718

14. Frohman LA (1978) The central nervous system and metabolic regulation. In: Katzen $H$, Mahler $\mathrm{R}$ (eds) Diabetes, obesity and vascular disease. Halsted Press, New York, p 493-515

15. Hill DE, Mayes S, DiBattista D, Lockhart-Ewart R, Martin JM (1977) Hypothalamic regulation of insulin release in rhesus monkeys. Diabetes 26: 726-731

16. McDonald TJ, Jornvall H, Nilsson G, Vagne M, Ghatei M, Bloom SR, Mutt V (1979) Characterization of a gastrin releasing peptide from porcine non-antral gastric tissue. Biochem Biophys Res Commun 90: 227-233 
17. Moltz JH, Dobbs RR, McCann SM, Fawcett CP (1977) Effects of hypothalamus factors in insulin and glucagon release from the islets of Langerhans. Endocrinology 101: 196-202

18. Moody TW, Pert CB (1979) Bombesin-like peptides in rat brain: Quantitation and biochemical characterization. Biochem Biophys Res Commun 90: 7-14

19. Moody TW, Pert CB, Rivier JE, Brown MR (1978) Bombesin: Specific binding to rat brain membranes. Proc Natl Acad Sci USA 75: 5372-5376

20. Pittman QJ, Taché Y, Brown M (1980) Bombesin acts in preoptic area to produce hypothermia in rats. Life Sci 26 : 725-730

21. Polak JM, Hobbs R, Bloom SR, Solcia E, Pearse AGE (1976) Distribution of a bombesin-like peptide in human gastrointestinal tract. Lancet II: 1109

22. Rivier J, Brown M (1978) Bombesin, bombesin analogs and related peptides: Effects on thermoregulation. Biochemistry 17: $1766-1771$

23. Smith PH, Porte D Jr (1976) Neuropharmacology of the pancreatic islets. Annu Rev Pharmacol Toxicol 16: 269-285

24. Smith JR, La Hann TR, Chestnut RM, Carino MA, Horita A (1977) Thyrotropin-releasing hormone: Stimulation of colonic

\section{Discussion after Brown's Presentation}

Niijima: How can you rule out the possibility that the epinephrine acts directly at the liver?

Brown: I make the assumption that at the doses we're using, in the rat, somatostatin has no effect on epinephrine's action at the liver but does block glucagon secretion. Therefore, when we give somatostatin peripherally to animals and inhibit both bombesin-induced and epinephrine-induced hyperglycaemia, the suggestion would be that the epinephrine is not acting directly at the liver, and that its effects are due to inhibition of glucagon secretion. My conclusion assumes that somatostatin has no direct effect at the liver to alter glucose production. Therefore, your suggestion remains possible, but unlikely.

Porte: In regard to that, there are direct effects at the liver in man, if not the rat. We have done studies in which we have given humans somatostatin to clamp the islet and then given replacement infusions of insulin and glucagon. If you then give epinephrine, there's a very significant hyperglycaemia. A similar experiment has been published (Am J Physiol (1979) 237: E 356-362).

Brown: But a clamp is only as good as your belief that the somatostatin is totally inhibiting the islet.

Porte: We also measured the concentrations of these peptides and they didn't change; yet epinephrine still caused a marked hyperglycaemia.

Brown: In humans, you could test this more precisely by giving propranolol. This can't be done in the rat because the rat allegedly has an alpha adrenergic receptor in the liver for epinephrine just like the B-cell. So the use of alpha-adrenergic blockers would provide only ambiguous data in the rat. In the human, however, epinephrine is activity following intracerebroventricular administration. Science 196: 660-662

25. Taché Y, Vale W, Brown M (1980) Brain peptidergic control of gastric secretions in rats. Fed Proc 39: 327

26. Vale W, Rivier J, Ling N, Brown M (1978) Biologic and immunologic activities and applications of somatostatin analogs. Metabolism 27: 1391-1401

27. Walsh JH, Holmquist AL (1976) Radioimmunoassay of bombesin peptides: identification of bombesin-like immunoactivity in vertebrate gut extracts. Gastroenterology 70: 948

28. Weitzman RE, Firemark H, Riviczky A, Nelson JC (1979) Hypotension following intraventricular somatostatin (SRIF) is mediated by lowering of plasma catecholamines. Endocrinology 104: 292

\section{Dr. M. Brown}

Peptide Biology Laboratory

The Salk Institute

San Diego, CA 92138

USA thought to act at beta adrenergic receptors in the liver, so propranolol might be useful.

Porte: It's probably much more complicated than you suggest because there are data indicating that the use of propranolol also changes the level of epinephrine in the blood; so the study you suggest would be hard to interpret. That's why we've gone to the clamp experiments in humans. I don't know what's happening in the rat. In the dog, Sherwin has reported that the effects of epinephrine at the liver, but not those of glucagon, are inhibited by somatostatin, therefore raising some questions regarding the lack of direct liver effects of somatostatin. (Am J Physiol (1979) 236: 113-119).

Niijima: Can you be certain that your bombesin is not acting peripherally?

Brown: Yes, we've given very large doses peripherally and never influenced epinephrine secretion. But you raise an interesting point about possible compartmentalization of functions in the body. The fact that some peptides do not cross the blood brain barrier puts them into a unique category well-suited for certain transmitter functions. Such compounds may play a particular kind of role in the body.

Shimazu: Have you administered epinephrine centrally as well as peripherally?

Brown: Yes, we've done that, and it had no effect.

Nicolaidis: Did I understand you to say that the somatostatin analogue you use is a totally selective blocker?

Brown: Let me explain what I mean. Peripherally, the analogue causes hyperglycaemia, probably via a rather selective inhibition of insulin relative to glucagon secretion 
at that dose. At higher doses, it inhibits both. At the dose given, then, the ratio of insulin to glucagon favours glucose production. In the brain, the effect is just the opposite.

B. Jeanrenaud: How much bombesin can you measure in the brain compared to the amount that you inject?

Brown: We generally inject at a range of 1 to $100 \mathrm{ng}$. The entire hypothalamus probably has a total of around $1 \mathrm{ng}$ of bombesin; but you must remember that when we administer compounds this way, exact doses become somewhat meaningless since a receptor located a small distance away sees a very different concentration than is released from the cannula. Very steep concentration gradients probably occur. Further, within synaptic clefts, concentrations of substances actually achieved may be very high, perhaps micromolar.

Uvnäs-Wallensten: Have you looked at enkephalins or other adrenal compounds in your system?

Brown: Yes, we've been interested in the differences between the hyperglycaemia induced by stress and by bombesin acting in the brain. The differences are not terribly obvious. The magnitude of the hyperglycaemia caused by bombesin far exceeds that caused by stress. Since the bombesin effect is totally eliminated by adrenalectomy, I sought other substances from the adrenals which might be contributing. There were reports that enkephalins are present in the adrenal medulla, so I first showed that the administration of enkephalins didn't alter the response. I then made a series of extractions from the adrenal of the rat and identified a substance which we called "adrenal hyperglycaemic factor" and which, like all factors, may or may not exist. The factor was catecholamine and steroidfree and still caused hyperglycaemia when administered to rats. When we moved to the bovine adrenal, we couldn't isolate such a factor, so we're presently pursuing these studies in the rat.

Uvnäs-Wallensten: Could any of your bombesin effect be due to steroids?

Brown: It's unlikely since hypophysectomy has no effect and we cannot measure any change of steroids in the experiments.

Uvnäs-Wallensten: What about neurotensin, since there's evidence that it's present in nerves to the adrenal?

Brown: I can't believe that there's enough neurotensin anywhere in the body to produce that much hyperglycaemia. Experiments demonstrating a peripheral effect of neurotensin to cause hyperglycaemia required micrograms. 